\title{
Modulation of the axial water hydrogen-bonding properties by chemical modification of the substrate in resting state, substrate- bound heme oxygenase from Neisseria meningitidis; Coupling to the distal H-bond network via ordered water molecules
}

\author{
Li-Hua Ma\#, Yangzhong Liu\#, Xuhong Zhang ${ }^{\dagger}$, Tadashi Yoshida ${ }^{\dagger}$, Kevin C. Langry\#, Kevin \\ M. Smith§, and Gerd N. La Mar ${ }^{\#,}$ \\ \#Department of Chemistry, University of California, Davis, California 95616 \\ $\dagger$ Department of Biochemistry, Yamagata University School of Medicine, Yamagata 990-9585, Japan \\ §Department of Chemistry, Louisiana State University, Baton Rouge, LA 70803
}

\begin{abstract}
The hydrogen bonding of ligated water in ferric, high-spin, resting-state substrate complexes of heme oxygenase from Neisseria meningitidis has been systematically perturbed by variable electronwithdrawing substituents on the hemin periphery. The pattern of ${ }^{1} \mathrm{H}$ NMR-detected dipolar shifts due to the paramagnetic anisotropy is strongly conserved among the four complexes, with the magnitude of dipolar shifts or anisotropy increasingly in the order of substituent formyl < vinyl < methyl. The magnetic anisotropy is axial and oriented by the axial Fe-His 23 bond, and, while individual anisotropies have uncertainties of $\sim 5 \%$, the relative values of $\Delta \chi$ (and the zero-field splitting constant, $\mathrm{D} \propto \Delta \chi_{\mathrm{ax}}$ ) are defined to $1 \%$. The unique changes in the axial field strength implied by the variable zero-field splitting are in accord with expectations for the axial water serving as a stronger H-bond donor in the order of hemin substituents formyl > vinyl > methyl. These results establish the axial anisotropy (and D) as a sensitive probe of the H-bonding properties of a ligated water in resting-state, substrate complexes of heme oxygenase. Correction of observed labile proton chemical shifts for paramagnetic influences indicates that Gln49 and His53, some 10Å from the iron, sense the change in the ligated water $\mathrm{H}$-bonding to the three non-ligated ordered water molecules that link the two side chains to the iron ligand. The present results augur well for detecting and characterizing changes in distal water H-bonding upon mutagenesis of residues in the distal network of ordered water molecules and strong H-bonds.
\end{abstract}

\section{Keywords}

H-bonding; ligated water; N. meningitidis; heme oxygenase; zero-field splitting; dipolar shifts; magnetic anisotropy

\section{INTRODUCTION}

Heme oxygenase ${ }^{1}, \mathrm{HO}^{1}$, is a non-metal enzyme $\mathrm{e}^{2-6}$ that uses heme as substrate and cofactor to cleave it at one meso position into biliverdin, iron and CO. The enzyme is present in mammals, plants and some pathogenic bacteria. The mammalian role includes iron homeostasis 
and the generation of biliverdin as autooxidant and $\mathrm{CO}$ as neural messenger, 5,7 while plants use $\mathrm{HO}$ to produce open tetrapyrroles as precursors to light harvesting antennae. ${ }^{8}$ In bacteria, the primary role appears to be for mining the "host's" iron necessary for infection. ${ }^{3,4}$ The mechanism of the $\mathrm{HO}$ reaction appears to be the same in the diverse HOs, where it is a ferric hydroperoxy heme, ${ }^{9,10}$ rather than the more common ferryl heme, that is the reactive species in converting heme into its first intermediate, meso-hydroxy heme. The various HOs exhibit not only significant sequence, but also structural, homology, as evidenced in crystal structures for HOs from mammals, 11,12 photosynthetic bacteria 13 and pathogenic bacteria. ${ }^{14-18}$ The selectivity of the ring cleavage on the $\alpha$-meso position in mammalian and plant HOs, and for all but one pathogenic bacterium, ${ }^{19}$ is controlled by both blocking three meso positions to attack by the close placement of the distal helix, and by steric "tilting"/directing the exogenous ligand (and presumably, $\mathrm{Fe}+{ }^{3}-\mathrm{OOH}$ ) toward the fourth meso position by the distal helix backbone. The stabilization of the unusual reactive ferric hydroperoxy species has been attributed to three largely conserved ordered water molecules, ${ }^{6,15}$ one of which provides the primary $\mathrm{H}$-bond donor/acceptor to the nascent $\mathrm{Fe}^{+2} \mathrm{O}_{2}$ and $\mathrm{Fe}^{+3}-\mathrm{OOH}$ species.

Solution ${ }^{1} \mathrm{H}$ NMR has shown ${ }^{20-26}$ that HOs possess a distal H-bond network, with several remarkably strong $\mathrm{H}$-bonds, that extends from the distal pocket to the $\mathrm{HO}$ surface, and that this network includes the three proposed "catalytic" water molecules, as well as numerous additional water $21-23,25$ molecules ordered within this network. Sequence comparison among the structurally and/or spectroscopically investigated HOs shows that human HO isozyme \#1 $(\mathrm{hHO})$, rat $\mathrm{HO}(\mathrm{rHO})$ and the bacterial $\mathrm{HO}$ from Corynebacterium diphtheriae $(\mathrm{Cd} \mathrm{HO})$ possess homologous H-bond networks which, due to significant substitution, differ from those of the bacteria from Neisseria meningitidis $(\mathrm{NmHO})$ or Pseudomonas aeruginosa $(\mathrm{PaHO})$, which, in turn are more similar to each other. ${ }^{4,} 6$ While each of the HOs exhibit three similarly, but not identically, placed water molecules in the distal pocket, it is not yet known how strongly these $\mathrm{H}$-bond networks and distal water molecules are coupled to the iron center and how this network may differentially respond to the generation of the reactive species and/or intermediates in the HO reaction. Sizable movement of heteroatoms of both water and distal residues, due to imposed perturbation introduced by mutagenesis of either the $\mathrm{HO}$ or substrate, can be readily detected in X-ray crystallography, but changes in $\mathrm{H}$-bond strength of the ordered water/H-bond network may be unresolved and would have to rely on ${ }^{1} \mathrm{H}$ NMR spectroscopy, $21,22,25-28$ where low-field bias of the labile proton chemical shift correlates with increased H-bond donor strengths.

A particularly suitable $\mathrm{HO}$ complex for investigating distal $\mathrm{H}$-bond interaction between a ligated and the distal non-ligted water molecules is the high-spin, ferric, resting state complex, HO-PH- $\mathrm{H}_{2} \mathrm{O}$. This complex, like similar metglobin complexes, 29 participates in an acid $\Leftrightarrow$ alkaline transition ${ }^{30-35}$ where the axial water molecule is deprotonated and the high-spin complex is converted to a largely low-spin, hydroxide complex (see Figure 1). Differential stabilization of the H-bonding of ligated water in different HOs is indicated by the variable $\mathrm{pK}$ in the range 8.0 to 9.0 in WT HOs, ${ }^{30-34}$ and their sensitivity to mutation for a given HO. ${ }^{36}$ However, the altered $\mathrm{pK}$ does not allow one to determine whether a reduced $\mathrm{pK}$ is due to destabilization of the $\mathrm{H}_{2} \mathrm{O}$ or stabilization of the $\mathrm{OH}^{-}$by $\mathrm{H}$-bonding. ${ }^{37}$ Hence it is desirable to explore the response of the distal $\mathrm{H}$-bonding of the ligated water upon perturbation in the interaction with a given $\mathrm{HO}-\mathrm{PH}-\mathrm{H}_{2} \mathrm{O}$ complex. Both optical ${ }^{38,39}$ and $\mathrm{NMR}^{40}$ spectroscopy have demonstrated that the $\mathrm{pK}$ for $\mathrm{H}_{2} \mathrm{O} \Leftrightarrow \mathrm{OH}^{-}$transition in metglobins, as depicted in Figure 1 , can be strongly modulated by peripheral substituents on the hemin, with electronwithdrawing (donating) substituents shifting the $\mathrm{pK}$ to lower (higher) $\mathrm{pH}$ values. Hence the ligated water $\mathrm{H}$-bond donor, or ligated hydroxide $\mathrm{H}$-bond acceptor, properties are readily perturbed by hemin substitution. In the absence of distal interaction, a ligated water (water $a$ in Figure 1a) is a weak-field ligand. Serving as a H-bond donor to a non-ligated water $b$ (or distal base) will increase the axial field strength, AFS, of the ligated water, which, in the limit 
of complete deprotonation (Figure 1B), yields the strong-field hydroxide ligand. The axial field strength, AFS, for a high-spin, ferric hemin is directly reflected ${ }^{41}$ in the zero-field splitting parameter D, and hence the AFS, with the value of D increasing in magnitude with decreases of the AFS.

The $\mathrm{D}$ values for hemins are too large $\left(5-20 \mathrm{~cm}^{-1}\right)$ to detect by any conventional $\mathrm{EPR},{ }^{41}$ but are readily observed in the ${ }^{1} \mathrm{H}$ NMR of high-spin ferric hemoproteins ${ }^{20,42-46}$ through the dipolar shifts for non-ligated residues. With the isotopic $\mathrm{g}=2$ value for ferric hemins, and the strong dominance of axial symmetry, $20,42-46$ the dipolar shifts for non-ligated residue protons are given by:

$$
\delta_{\mathrm{dip}}=-\left(12 \mu_{0} \pi \mathrm{N}_{\mathrm{A}}\right)^{-1} \Delta \chi_{\mathrm{ax}}\left(3 \cos ^{2} \theta^{\prime}-1\right) \mathrm{R}^{-3} \Gamma(\alpha, \beta, \gamma)
$$

where $\Delta \chi_{\mathrm{ax}}$ is given by: $46-48$

$$
\Delta \chi_{\mathrm{ax}}=-\frac{21 \mathrm{~g}^{2} \mathrm{~B}^{2} \mathrm{~N}_{\mathrm{A}}}{5 \mathrm{k}^{2}} \mathrm{D} / \mathrm{T}^{2},
$$

with $\mathrm{B}=$ Bohr magneton, $\mathrm{k}=$ Boltzmann constant, $\mathrm{N}_{\mathrm{A}}=$ Avogadro's number, $\mathrm{g}=$ spectroscopic splitting factor $=\sim 2.0$, and $\theta^{\prime}, \mathrm{R}$ are the coordinates of a proton in a convenient reference coordinate system ( $x^{\prime}, y^{\prime}, z^{\prime}$ in Figure 2$) . \Gamma(\alpha, \beta, \gamma)$ is the Euler rotation that provides the orientation of the unique axis in the molecular framework. The overwhelming dominance of the zero-field splitting contribution to $\Delta \chi$, manifested $42,43,45-48$ in strictly $\mathrm{T}^{-2}$ dependence of $\delta_{\text {dip }}(\mathrm{obs})$ and the axial anisotropy, have been established ${ }^{26}$ for the $N m \mathrm{HO}-\mathrm{P} \mathrm{H}-\mathrm{H}_{2} \mathrm{O}$ complex, as well as several other high-spin ferric hemoproteins. $42,43,45$ The necessary NMR protocols for definitively assigning the strongly relaxed dipolar-shifted residues, 26,48 and the conversion of these dipolar shifts to a quantitative $\Delta \chi_{\mathrm{ax}}$ and $\mathrm{D}$ have been presented.

In order to assess the prospects for characterizing the influence of point mutation on the distal H-bond network, we initiate here the study of the influence of "mutation" of the substrate periphery on the NMR spectral properties of high-spin ferric $\mathrm{NmHO}-\mathrm{PH}-\mathrm{H}_{2} \mathrm{O},{ }^{26}$ (where $\mathrm{PH}$ is protohemin, i.e., Figure 2 with $\mathrm{R}_{2}=\mathrm{R}_{4}=$ vinyl). We utilize three modified hemins, in addition to native protohemin, $\mathrm{PH}\left(\mathrm{R}_{2}=\mathrm{R}_{4}=\right.$ vinyl), 2,4-dimethyldeuterohemin, $\mathrm{DMDH}\left(\mathrm{R}_{2}=\mathrm{R}_{4}=\right.$ methyl in Figure 2), 2-methyl,4-vinyldeuterohemin, $2 \mathrm{M} 4 \mathrm{VDH}\left(\mathrm{R}_{2}=\right.$ methyl, $\mathrm{R}_{4}=$ vinyl in Figure 2), and 2-formyl,4-vinyldeuterohemin, $2 \mathrm{~F} 4 \mathrm{MDH}\left(\mathrm{R}_{2}=\right.$ formyl, $\mathrm{R}_{4}=$ vinyl in Figure 2; also called Spirographis hemin). Our initial investigation focuses on the questions; can changes in $\Delta \chi_{\mathrm{ax}}$ (D) with modified hemin be detected? How well can relative $\Delta \chi_{\mathrm{ax}}$ (D) values be quantitated? How far, and how selectively, do the altered $\mathrm{H}$-bond properties of the axial water, reflected in $\Delta \chi_{\mathrm{ax}}$ (D) values, propagate into the distal H-bond network?

\section{EXPERIMENTAL}

\section{Enzyme preparation}

The apo-NmHO samples used in this study are the same as described in detail previously. ${ }^{25}$ Stoichiometric amounts of the four hemins of interest, dissolved in $0.1 \mathrm{M} \mathrm{KOH}$ in ${ }^{1} \mathrm{H}_{2} \mathrm{O}$, were added to apo- $\mathrm{NmHO}$ in phosphate buffer (100 mM, pH 6.8-7.0). The three modified hemins used (in addition to protohemin $\left(\mathrm{R}_{2}=\mathrm{R}_{4}=\right.$ vinyl in Figure 2), 2,4-dimethyldeuterohemin, $\operatorname{DMDH}\left(\mathrm{R}_{2}=\mathrm{R}_{4}=\right.$ methyl in Figure 2), 2-methyl,4-vinyldeuterohemin, $2 \mathrm{M} 4 \mathrm{VDH}\left(\mathrm{R}_{2}=\right.$ methyl, $\mathrm{R}_{4}=$ vinyl in Figure 2) and Spirographis or 2-formyl,4-vinyldeuterohemin, 2F4VDH $\left(\mathrm{R}_{2}=\right.$ formyl, $\mathrm{R}_{4}=$ vinyl in Figure 2$)$, are the same as those reported previously. ${ }^{21,49}$ The substrate complexes were purified by column chromatography on Sephadex G25 and yielded samples $\sim 3 \mathrm{mM}$ in $\mathrm{NmHO}-\mathrm{PH}-\mathrm{H}_{2} \mathrm{O}$ at pH6.8- 7.0. Samples in ${ }^{1} \mathrm{H}_{2} \mathrm{O}$ were converted to ${ }^{2} \mathrm{H}_{2} \mathrm{O}$ by column chromatography. 50 


\section{NMR spectroscopy}

${ }^{1} \mathrm{H}$ NMR data were collected on Bruker AVANCE 500 and 600 spectrometers operating at 500 and $600 \mathrm{MHz}$, respectively. Reference spectra at $500 \mathrm{MHz}$ were collected in ${ }^{1} \mathrm{H}_{2} \mathrm{O}$ and ${ }^{2} \mathrm{H}_{2} \mathrm{O}$ over the temperature range $10-35^{\circ} \mathrm{C}$ at repetition rates of $1 \mathrm{~s}^{-1}$ (14 and $22 \mathrm{ppm}$ bandwidths), and $5 \mathrm{~s}^{-1}$ (200 ppm bandwidth) using a standard one-pulse sequence, as well as with 3:9:19 "soft" pulse detection 51 with and without saturation of the water solvent signal. Chemical shifts are referenced to 2,2-dimethyl-2-silapentane-5-sulfonate (DSS) through the water resonance calibrated at each temperature. Non-selective $T_{1} \mathrm{~s}$ were estimated in both ${ }^{1} \mathrm{H}_{2} \mathrm{O}$ and ${ }^{2} \mathrm{H}_{2} \mathrm{O}$ at $25^{\circ}$ from the null point of a standard inversion-recovery pulse sequence. $600 \mathrm{MHz}$ NOESY 52 spectra (mixing time, $40 \mathrm{~ms}$ ) and $500 \mathrm{MHz}$ Clean-TOCSY (to suppress ROESY response $^{53}$ ) spectra (spin lock 15 and $25 \mathrm{~ms}$ ) using MLEV-17 ${ }^{54}$ were recorded over a bandwidth of $15 \mathrm{KHz}$ (NOESY) and $12 \mathrm{KHz}$ (TOCSY) with recycle rates of $1 \mathrm{~s}^{-1}-5 \mathrm{~s}^{-1}$, using $512 \mathrm{t} 1$ blocks of 256 or 512 scans, each consisting of $2048 \mathrm{t} 2$ points. 2D data sets were processed using Bruker XWIN software on a Silicon Graphics Indigo workstation and consisted of $30^{\circ}$ or $45^{\circ}$-sine-squared-bell-apodization in both dimensions, and zero-filling to 2048 x 2048 data points prior to Fourier transformation.

\section{Magnetic axes determination}

The location of the magnetic axes were determined by finding the Euler rotation angles, $\Gamma(\alpha$, $\beta, \gamma)$, that rotate the crystal-structure based, iron-centered reference coordinate system, $x^{\prime}, y^{\prime}$, $\mathrm{z}^{\prime}$, into the magnetic coordinate system, $\mathrm{x}, \mathrm{y}, \mathrm{z}$, where the paramagnetic susceptibility tensor, $\chi$, is diagonal, where $\alpha, \beta, \gamma$ are the three Euler angles. ${ }^{48,55,56}$ The angle $\beta$ dictates the tilt of the major magnetic axis, $\mathrm{z}$, from the heme normal z', $\alpha$ reflects the direction of this tilt, and is defined as the angle between the projection of the $\mathrm{z}$ axis on the heme plane and the $\mathrm{x}$ ' axis (Figure 2), and $\kappa \sim \alpha+\gamma$ is the angle between the projection of the $\mathrm{x}, \mathrm{y}$ axes onto the heme plane and locates the rhombic axes (Figure 2). In the present case, the tensor is axially symmetric, $26,42-45$ so that $\Delta \chi_{\mathrm{rh}}=0$, and $\gamma(\kappa)$ becomes irrelevant. The magnetic axes were determined by a least-square search for the minimum in the error function, $\mathrm{F} / \mathrm{n}: 26,48,55,56$

$$
\mathrm{F} / \mathrm{n}=\sum_{\mathrm{i}=1}^{\mathrm{n}} \mid \delta_{\text {dip }}(\mathrm{obs})-\left.\delta_{\text {dip }}(\text { calc })\right|^{2}
$$

where the calculated dipolar shift in the reference coordinate system, $x^{\prime}, y^{\prime}, z^{\prime}$, or R, $\theta^{\prime}$, is given by Eq. (1) where $\Delta \chi_{\mathrm{ax}}$ is the axial anisotropy of the diagonal, axially symmetric paramagnetic susceptibility tensor. The observed dipolar shift, $\delta_{\mathrm{dip}}(\mathrm{obs})$, is given by:

$$
\delta_{\text {dip }}(\text { obs })=\delta_{\text {DSS }}(\text { obs })-\delta_{\text {DSS }}(\text { dia })
$$

where $\delta_{\mathrm{DSS}}(\mathrm{obs})$ and $\delta_{\mathrm{DSS}}(\mathrm{dia})$ are the chemical shifts, in ppm, referenced to DSS, for the paramagnetic $\mathrm{NmHO}-\mathrm{PH}-\mathrm{H}_{2} \mathrm{O}$ complex and an isostructural diamagnetic complex, respectively. In the absence of an experimental $\delta_{\mathrm{DSS}}(\mathrm{dia})$ for non-labile protons, it may be reliably estimated 57,58 from the available molecular structure 14 and available computer programs 57,58 as described previously for both $N m \mathrm{HO}-\mathrm{PH}-\mathrm{CN}^{25}$ and $N m \mathrm{HO}-\mathrm{PH}-\mathrm{H}_{2} \mathrm{O}{ }^{26}$ The calculated $\delta_{\mathrm{DSS}}(\mathrm{dia})$ are estimated to be reliable to $\pm 0.5 \mathrm{ppm}$. Since the errors are random, the uncertainties in $\delta_{\mathrm{DSS}}(\mathrm{dia})$ appear primarily in the deviations from the straight line expected in a plot of $\delta_{\text {dip }}(\mathrm{obs})$ vs $\delta_{\text {dip }}(\mathrm{calc})$, and have only a small influence on the uncertainties in the $\delta_{\text {dip }}($ calc) resulting from an optimized set of magnetic axes and anisotropies. The uncertainties in $\delta_{\text {dip }}$ (calc) are estimated at $\pm 15 \%$. 


\section{RESULTS \& DISCUSSION}

\section{Substrate resonances}

The resolved portions of the $500 \mathrm{MHz}{ }^{1} \mathrm{H}$ NMR spectra of the $\mathrm{NmHO}$-hemin- $\mathrm{H}_{2} \mathrm{O}$ complexes of DMDH, 2M4VDH, PH and 2F4VDH are illustrated in Figures 3A, 3B, 3C and 3D, respectively. In the low-field portion, the positions of the heme methyls are indicated by labels $\mathrm{M}$ (individually assigned ${ }^{26}$ only for $\mathrm{PH}$, shown as $\mathrm{M}_{\mathrm{i}}, \mathrm{i}=$ position on hemin in Figure 2 ). Heme methyl and $\mathrm{H}_{\alpha} \mathrm{s}$ of propionates, vinyl and formyl substituents, in the 90-30 ppm window exhibit $\mathrm{T}_{1} \mathrm{~s} \sim 4-6 \mathrm{~ms}$, which are typical of high-spin ferrihemoproteins ${ }^{48}$ and similar to those reported previously for $\mathrm{NmHO}-\mathrm{PH}-\mathrm{H}_{2} \mathrm{O} .26$ The upfield portion of the spectra reveals the 4-vinyl $\mathrm{H}_{\beta} \mathrm{S}$ for the 2M4VDH and 2F4VDH complexes. The chemical shifts for heme substituents are tabulated in Supporting Information. The variable spread of the largely contact-shifted pyrrole substituents among the four substrate complexes reflect primarily the spin density distribution due to the asymmetric positions of the variable electron withdrawing vinyl and formyl groups. 48, 59 Similar spreads of the signals are observed for the chromophore outside the protein matrix,${ }^{60}$ such that the heme peaks provide little new information on the interaction of substrate with HO.

The DMDH substrate outside the protein matrix exhibit a very small spread of the heme methyl shifts 49,59 since all eight pyrrole substituents are alkyl groups, rendering the heme effectively axially symmetric. The small spread of these methyls in $\mathrm{NmHO}-\mathrm{DMDH}-\mathrm{H}_{2} \mathrm{O}$ attests to the relatively small rhombic perturbation that the $\mathrm{NmHO}$ matrix exerts on the heme contact shift pattern.

\section{Axial His23 resonances}

The resonance at $\sim 28 \mathrm{ppm}$ in $\mathrm{NmHO}-\mathrm{PH}-\mathrm{H}_{2} \mathrm{O}$ has been assigned ${ }^{26}$ to the axial $\mathrm{His}_{\mathrm{C}} \mathrm{H}$ in $\mathrm{NmHO}-\mathrm{PH}-\mathrm{H}_{2} \mathrm{O}$ on the basis of the characteristically shorter $\mathrm{T}_{1}(\sim 2 \mathrm{~ms})$ than for pyrrole $\mathrm{C}_{\alpha} \mathrm{Hs}$ (4-6 ms). 48 Comparison of the four NMR traces in Figure 3 shows that the hyperfine shifts for this His $23 \mathrm{C}_{\beta} \mathrm{H}$ peak exhibits only a very small variation among the four complexes. However, the contact shift for this proton, obtained via:

$$
\delta_{\text {con }}=\delta_{\text {DSS }}(\text { obs })-\delta_{\text {DSS }}(\text { dia })-\delta_{\text {dip }}(\text { calc }),
$$

leads to $\delta_{\text {con }}$ values of 35.6, 36.2, 35.2 and $32.9 \mathrm{ppm}$ for the DMDH, 2M4VDH, PH and $2 \mathrm{~F} 4 \mathrm{VDH}$ complexes, respectively. While even the $\delta_{\text {con }}$ shifts are quite similar, it does appear that the Fe-His 23 covalency is somewhat reduced upon introducing the strongly electronwithdrawing formyl substituent in the $\mathrm{NmHO}-2 \mathrm{~F} 4 \mathrm{VDH}-\mathrm{H}_{2} \mathrm{O}$ complex. Such a response is consistent with the results obtained for $\Delta \chi_{\mathrm{ax}}$ values below.

\section{Residue assignments}

The upfield portions of the spectra in Figure 3 exhibit one well-resolved methyl peak previously assigned 26 to Leu142 $\mathrm{C}_{\delta 2} \mathrm{H}_{3}$ in the $\mathrm{NmHO}-\mathrm{PH}-\mathrm{H}_{2} \mathrm{O}$ complex. Comparison of the four complexes in Figure 3 shows that the upfield bias, and hence the magnitude of the upfield dipolar shift, decreases monotonically in the order DMDH $>2 \mathrm{M} 4 \mathrm{VDH}>\mathrm{PH}>2 \mathrm{~F} 4 \mathrm{VDH}$. Comparison of NOESY (see Figure 4) and TOCSY (not shown; see Supporting Information) maps among the four complexes reveals that all protons with significant dipolar shifts exhibit the same pattern of contacts among each other, dictating that active site molecular structure is conserved. Hence all residues assigned in detail for $\mathrm{NmHO}-\mathrm{PH}-\mathrm{H}_{2} \mathrm{O}$ are very straightforwardly transferred to each of the new target complexes using the identical 2D data described in detail for $\mathrm{NmHO}-\mathrm{PH}-\mathrm{H}_{2} \mathrm{O} .{ }^{26}$ The remainder of the chemical shift data are provided in Supporting Information. 
The chemical shifts for residues in the four complexes with at least one proton with $\delta_{\text {dip }}>|1.0|$ $\mathrm{ppm}$ are listed in Table 1. It is noted in Table 1 that all resonances with significant dipolar shift exhibit monotonic decreases of $\delta_{\text {dip }}(\mathrm{obs})$ in the same order as the Leu $142 \mathrm{C}_{\delta 2} \mathrm{H}_{3}$ signal in Figure 3, dictating that the electronic structure (magnetic properties) are systematically perturbed. This systematic effect on dipolar shifts is well-illustrated in the high-field resolved portion of the two complexes $\mathrm{NmHO}-2 \mathrm{~F} 4 \mathrm{VDH}-\mathrm{H}_{2} \mathrm{O}$ (Figure 4A) and $\mathrm{NmHO}-\mathrm{DMDH}-\mathrm{H}_{2} \mathrm{O}$ (Figure 4B), the substrates with the extreme difference in the degree of electron withdrawing power of the substituents. The trend is also obvious in the chemical shifts in Table 1.

The NOESY connectivities among the upfield shifted residues in $N m \mathrm{HO}-\mathrm{DMDH}-\mathrm{H}_{2} \mathrm{O}$ is shown in Figures 4C-4F. The low-field portion of the NOESY spectra for NmHO-DMDH$\mathrm{H}_{2} \mathrm{O}$ (not shown, see Supporting Information) reveals the conserved pattern of NOESY cross peaks among the labile proton involved in the robust $\mathrm{H}$-bonds in the distal pocket relative to that reported 26 for $\mathrm{NmHO}-\mathrm{PH}-\mathrm{H}_{2} \mathrm{O}$. Similar data for $\mathrm{NmHO}-2 \mathrm{~F} 4 \mathrm{VDH}-\mathrm{H}_{2} \mathrm{O}$ are provided in Supporting Information. The NOESY cross peak pattern for the Gln49, His53 side chains to Val81 and Leu142 (see Supporting Information), as previously found for $\mathrm{NmHO}-\mathrm{PH}-\mathrm{CN}^{25}$ and $\mathrm{NmHO}-\mathrm{PH}-\mathrm{H}_{2} \mathrm{O}^{26}$ dictates that the Gln49 and His53 side chains in solution exhibit $180^{\circ}$ rotation about the $\beta$ - $\gamma$ bond relative to those described in either crystal structure. ${ }^{14}, 15$ The chemical shift data for Gln49 and His53 are included in Table 1. The data in Table 1 demonstrate clearly that even subtle perturbations such as changing the electron withdrawing characteristic of a substrate substituent leads to detectable and systematic changes in the dipolar shift pattern for the structurally conserved protein matrix.

The chemical shifts for residues with a proton with $\delta_{\text {dip }}>|1.0|$ that is assigned in at least the DMDH, PH and 2F4VDH complexes are listed in Table 1 where we also list the $\delta_{\text {dip }}$ (calc) for the previously reported magnetic axes of $N m \mathrm{HO}-\mathrm{PH}-\mathrm{H}_{2} \mathrm{O}$. While the majority of the same residues were assigned in all four complexes, the systematically much smaller $\delta_{\text {dip }}$ for the $2 \mathrm{FV} 4 \mathrm{DH}$ than the $\mathrm{PH}$ or DMDH complexes resulted in somewhat poorer resolution, and hence provided slightly fewer definitive assignments. Similar data on other assigned residues are provided in Supporting Information.

\section{Magnetic axes determination}

Inspection of the chemical shifts in Table 1 shows that observed shift changes in direction (upor down-field) and magnitude with substrate substituent (basicity) are approximately proportional to the sign and magnitude of the calculated dipolar shift for the $\mathrm{NmHO}-\mathrm{PH}-\mathrm{H}_{2} \mathrm{O}$ complex (given for $\mathrm{PH}$ in the last column of Table 1), with the inferred dipolar shift magnitude increasing in the order 2F4VDH $<\mathrm{PH}<2 \mathrm{M} 4 \mathrm{VDH}<\mathrm{DMDH}$. Hence these chemical shift changes must reflect some systematic variation in the anisotropy and/or orientation of $\chi$ with substrate. This trend is more quantitatively assessed in the magnetic anisotropies obtained by minimizing the error function in Eq. (3).

The $\chi$ tensor for $\mathrm{NmHO}-\mathrm{PH}-\mathrm{H}_{2} \mathrm{O}$ was shown ${ }^{26}$ to be axial, with $\Delta \chi_{\mathrm{ax}}=-2.52 \pm 0.07 \times 10^{-8}$ $\mathrm{m}^{3} / \mathrm{mol}$, tilted from the heme normal by $\beta=7 \pm 1^{\circ}$, in a direction defined by $\alpha=210 \pm 10^{\circ}$ in Figure 2. The tilt magnitude and direction were shown to be the same as that for the Fe$\mathrm{N}_{\varepsilon}$ (His23) vector in the $\mathrm{NmHO}-\mathrm{PH}-\mathrm{H}_{2} \mathrm{O}$ crystal, ${ }^{14}$ confirming the reasonable expectation that the major magnetic axis is defined by the axial bond. Three parameter searches for the four complexes, using a variety of the available $\delta_{\text {dip }}(\mathrm{obs})$, yield very good correlation between $\delta_{\text {dip }}(\mathrm{obs})$ and $\delta_{\text {dip }}$ (calc) (see Figure 5) and result in the following $\left(\Delta \chi_{\mathrm{ax}}, \beta, \alpha\right)$ for DMDH, 2M4VDH, PH and 2F4VDH complexes $\left(-2.71 \pm 0.08 \times 10^{-8} \mathrm{~m}^{3} / \mathrm{mol}, \beta=9 \pm 1^{\circ}, \alpha=195 \pm\right.$ $\left.10^{\circ}\right),\left(-2.59 \pm 0.08 \times 10^{-8} \mathrm{~m}^{3} / \mathrm{mol}, \beta=7^{\circ} \pm 1^{\circ}, \alpha=200 \pm 10^{\circ}\right),\left(-2.52 \pm 0.08 \times 10^{-8} \mathrm{~m}^{3} / \mathrm{mol}, \beta\right.$ $\left.=8 \pm 1^{\circ}, \alpha=210 \pm 10^{\circ}\right)$ and $\left(\Delta \chi_{\mathrm{ax}}=-1.98 \pm 0.09 \times 10^{-8} \mathrm{~m}^{3} / \mathrm{mol}, \beta=10 \pm 2^{\circ}, \alpha=200 \pm 15^{\circ}\right)$. Inspection of these resulting parameters reveals that the orientation of the $\chi$ tensor is, in fact, essentially conserved, with a mean orientation defined by a tilt $\beta=8.5 \pm 15^{\circ}$ in a direction $\alpha$ 
$=200 \pm 15^{\circ}$. When we restrict $\alpha$ and $\beta$ to the values determined by the axial His $23 \mathrm{~N} \varepsilon$-Fe vector, as determined for $\mathrm{NmHO}-\mathrm{PH}-\mathrm{H}_{2} \mathrm{O},{ }^{26}$ the one-parameter search results in the relative $\Delta \chi_{\mathrm{ax}}$ value $-2.64 /-2.58 /-2.52 /-2.02$, in $10^{-8} \mathrm{~m}^{3} / \mathrm{mol}$, each with $\pm 0.08 \times 10^{-8} \mathrm{~m}^{3} / \mathrm{mol}$ uncertainties for DMDH/2M4VDH/PH/2F4VDH, respectively. The individual values of $\Delta \chi$ vary by as much as $4 \%$ upon selecting different input data, indicating that any single $\Delta \chi_{\mathrm{ax}}$ will not be better defined than to $\pm 0.08 \times 10^{-8} \mathrm{~m}^{3} / \mathrm{mol}$. However, while individual values can vary by $\sim 5 \%$, the relative $\Delta \chi_{\mathrm{ax}}(\mathrm{D})$ values among the four complexes for any one set of input data (normalized to $\mathrm{PH}$ ) are remarkably reproducible as: $1.08 \pm 0.01 / 1.04 \pm 0.01 / 1: 00 / 0.82 \pm 0.2$ for the $\mathrm{DMDH} /$ $2 \mathrm{M} 4 \mathrm{VDH} / \mathrm{PH} / 2 \mathrm{~F} 4 \mathrm{VDH}$ complexes. Thus relative values are much more better defined than the absolute values of $\Delta \chi_{\mathrm{ax}}$. With $\mathrm{D}=9.1 \mathrm{~cm}^{-1}$ reported for the $N m \mathrm{HO}-\mathrm{PH}-\mathrm{H}_{2} \mathrm{O}$ complex, ${ }^{26}$ the D value for the complexes with DMDH, 2M4VDH and 2F4VDH are 9.8, 9.5 and 7.5 $\mathrm{cm}^{-1}$, respectively.

On the basis of these results, we can conclude that, since the axial field strength inversely correlates with $\mathrm{D}\left(\Delta \chi_{\mathrm{ax}}\right.$ magnitude $\left.{ }^{41}\right)$, the AFS varies in the order $2 \mathrm{~F} 4 \mathrm{VDH}>\mathrm{PH}>2 \mathrm{M} 4 \mathrm{VDH}$ $>$ DMDH. The strongest AFS arising from the substrate with the most electron-withdrawing substituents is completely consistent with the expectation of such a perturbation in the $\mathrm{H}$-bond donor strength of the axial water, 37 as observed in the decrease in the pK value for the $\mathrm{H}_{2} \mathrm{O}$ > $\mathrm{OH}^{-}$conversion in metglobins. ${ }^{38-40}$ The present data, however, detect only the changes in the stabilization of the aquo complex. The trend in $\Delta \chi$ correlates well with the Hammet ${ }^{61} \sigma_{p}$ substituent parameters that predicts the basicity of the substrate, as shown in Figure 6 . The fact that the $\Delta \chi(\mathrm{D})$ values for 2MV4DH complex are midway between those of DMDH and $\mathrm{PH}$ complexes demonstrates that the two vinyl groups contribute equally to the basicity of $\mathrm{PH}$ relative to DMDH. The strongest AFS for the $2 \mathrm{~F} 4 \mathrm{VDH}$ complex is consistent with the observation that the axial His $23 \mathrm{C}_{\beta} \mathrm{H}$ contact shift, and hence Fe-His covalency, is slightly reduced relative to the other three substrates, as expected from the trans-effect. ${ }^{62}$ It is expected that, as additional assignments become available on ${ }^{15} \mathrm{~N}$ - and/or ${ }^{15} \mathrm{~N} /{ }^{13} \mathrm{C}$ labeled $N m \mathrm{HO}$ complexes, the uncertainties in both absolute and relative values of $\Delta \chi_{\mathrm{ax}}$ can be reduced. However, the uncertainties in the individual $\Delta \chi(\mathrm{D})$ values will always be greater than in the relative values for a given $\mathrm{HO}$ with a variety of substituents.

\section{H-bond strengths}

It is noted that, because of variable $\mathrm{H}$-bonding, $\delta_{\mathrm{DSS}}(\mathrm{dia})$ for labile protons cannot be reliably estimated by the shift X program. ${ }^{25,57}$ Hence, comparison of H-bond strength among the four substrates requires the determination of $\delta^{\mathrm{DSS}}\left(\mathrm{dia}^{*}\right)$, the chemical shifts for a labile proton in the absence of paramagnetism, which we define by:

$$
\delta_{\text {DSS }}\left(\mathrm{dia}^{*}\right)=\delta_{\text {DSS }}(\mathrm{obs})-\delta_{\text {dip }}(\text { calc })
$$

where $\delta_{\text {dip }}(\mathrm{calc})$ for the different substrates is obtained for each set of magnetic axes. A list of the $\delta_{\mathrm{DSS}}\left(\mathrm{dia}^{*}\right)$ for labile protons for peptide NHs and important side chains that depend significantly on substituents is provided in Table 2 . Also included for comparison are the range of $\delta_{\mathrm{DSS}}(\mathrm{obs})$ and $\Delta \delta_{\mathrm{DSS}}(\mathrm{obs})$ and the range of the calculated $\Delta \delta_{\mathrm{DSS}}\left(\mathrm{dia}^{*}\right)$, as well as the $\delta_{\text {dip }}\left(\right.$ calc) for the PH complex. ${ }^{26}$ The X-Y distance in X-H ... Y H-bond has been shown ${ }^{27}$ to correlate with the extent of low-field bias on the labile proton chemical shift, $\delta_{\mathrm{DSS}}\left(\mathrm{dia}^{*}\right)$, and this distance inversely relates to H-bond strength. ${ }^{28}$ Hence increased low-field bias of labile proton chemical shift can be taken as evidence for increased H-bond strength.

The reliability of the determined $\delta_{\mathrm{DSS}}\left(\mathrm{dia}^{*}\right)$ is strongly supported by the fact that for the numerous peptide NHs which exhibit significantly different chemical shifts $\left(\Delta \delta_{\mathrm{DSS}}(\mathrm{obs} *)\right.$ in Table 2) with 2,4-substitution in Table 2 , correction for $\delta_{\text {dip }}$ (calc) shows that $\delta_{\mathrm{DSS}}\left(\mathrm{dia}{ }^{*}\right)$, and hence H-bonding, is essentially independent of substrates for all but one notable exception, 
Glu115. The Glu115 $\delta_{\text {DSS }}\left(\right.$ dia $\left.^{*}\right)$ argues for increased H-bond strength in the order DMDH < $2 \mathrm{M} 4 \mathrm{VDH}<\mathrm{PH}<2 \mathrm{~F} 4 \mathrm{VDH}$. The Glu115 side chain serves as an acceptor to the side chain of one of two residues, Asn118 or Arg77, with the former favored for the $\mathrm{H}$-bond donor $\mathrm{H}_{2} \mathrm{O}$ ligand, and the latter for the H-bond acceptor NO ligands, 14,15 and a change of the position of the equilibrium could selectively perturb the Glu115 NH H-bond strength. A similar anomalous difference in the Glu115 NH H-bond strength was detected for the NmHO-PH$\mathrm{CN}^{25}$ and $\mathrm{NmHO}-\mathrm{PH}-\mathrm{H}_{2} \mathrm{O}^{26}$ complexes.

Among the side chain NHs, moderate systematic differences in $\delta_{\mathrm{DSS}}$ (obs) for the His141 $\mathrm{N}_{\delta 1} \mathrm{H}$ and Trp153 $\mathrm{N}_{\varepsilon} \mathrm{H}$ are removed by correcting for $\delta_{\text {dip }}$ (calc), to demonstrate completely conserved H-bond strength. For the Gln49 and His53 side chain, however, significant systematic differences in $\delta_{\mathrm{DSS}}(\mathrm{obs})$ are only partially decreased in $\delta_{\mathrm{DSS}}(\mathrm{dia} *)$, suggesting slightly increasing $\mathrm{H}$-bond strength for both side chains upon introduction of electronwithdrawing substituents in the substrate. The position of three catalytically implicated, ordered water molecules (\#37, 77 and 243 in the crystal ${ }^{14}$ ) (yellow spheres), the ligated water (green sphere) and residues that interact directly or indirectly with these water molecules, are shown in Figure 7. The direction (H-donor $\rightarrow$ acceptor) of $\mathrm{H}$-bond are shown as arrows in those cases where crystallography ${ }^{14}$ or solution $\mathrm{NMR}^{26}$ data provide information on the location of the proton. For other interactions where this information is not available, or ambiguous, likely $\mathrm{H}$-bond interactions are shown by dashed lines. Since the ligated water \#1 and the side chains of both $\mathrm{G} \ln 49 \mathrm{~N}_{\varepsilon} \mathrm{H}_{2}$ and His53 ring interact primarily as $\mathrm{H}$-bond donors to ordered water molecules (Figure 7) the simplest expectation would be that increased H-bond donation of ligated $\mathrm{H}_{2} \mathrm{O}$ in the $2 \mathrm{~F} 4 \mathrm{VDH}$ (relative to the other heme) complex will result in reduced $\mathrm{H}$-bond donation by the two side chains, contrary to observation. Such an expected behavior is clearly observed 63 in the $N m \mathrm{HO}-\mathrm{PH}-\mathrm{H}_{2} \mathrm{O}$ conversion to $\mathrm{NmHO}-\mathrm{PH}-\mathrm{OH}$.

Two points may be relevant to this apparent paradox. One is that the Gln49 and His53 H-bonds and the three ordered water molecules depicted in Figure 7 are only a portion of a more extensive network of ordered water molecules and strong H-bonds, and the small changes in $\mathrm{H}$-bond strength are the result of optimizing the network when increasing H-bond donor strength of the ligated water upon replacing DMDH by $2 \mathrm{~F} 4 \mathrm{VDH}$. The second point is that, although the determined magnetic axes for the four complexes equally well account for the pattern of dipolar shift, the Gln49 and His53 side chain (more so the former) are placed relatively close to the node in the dipolar field, such that their $\delta_{\text {dip }}($ calc) values are more sensitive to small changes in structure (or uncertantities in $\delta_{\text {dip }}($ calc)), than the other residues. We have shown 22 for hHO-PH-CN that peptide $\mathrm{NH}$ in strong $\mathrm{H}$-bonds exhibit much larger ${ }^{15} \mathrm{~N}$ than ${ }^{1} \mathrm{H}$ chemical shift changes, in ppm, upon altering $\mathrm{H}$-bond strength. Since $\delta_{\text {dip }}\left(\right.$ calc) for the ${ }^{15} \mathrm{~N}$ is comparable to $\delta_{\text {dip }}$ (calc) for ${ }^{1} \mathrm{H}$ in a peptide $\mathrm{NH},{ }^{15} \mathrm{~N}$ will more unambiguously characterize the H-bond change for Gln49 and His53 than presently possible. Efficient routes to ${ }^{15} \mathrm{~N}$ labeling of $\mathrm{NmHO}$ are under investigation. The additional assignments accessed with ${ }^{15} \mathrm{~N}$-labeled $\mathrm{NmHO}$ will also provide additional data that will more quantitatively describe the magnetic axes in the complex of interest.

\section{CONCLUSIONS}

The present results demonstrate that changes in the H-bond properties in the ligated water are readily detected, and reasonably quantitated, by ${ }^{1} \mathrm{H}$ NMR in high-spin, resting state HOsubstrate complexes. The expected increase in ligated water as H-bond donor strength, and hence, increased effective axial field strength of the heme, with increased electron withdrawing power of substrate substituent, is observed in the decrease of the axial magnetic anisotropy (and zero-field splitting parameter D). Moreover, apparent influences of the altered H-bonding of the axial water, appears to be transmitted to at least two residues some $10 \AA$ from the iron. His53 is the residue homologous to Tyr58 in mammalian HO whose mutagenesis abolishes 
PH cleavage. ${ }^{64,65}$ There is good reason to be optimistic that mutagenesis of the member residues of the distal H-bond network should lead to similarly perturbed $\Delta \chi(\mathrm{D})$ values that would shed light on the link between the axial water molecule and the distal network of ordered water molecules and H-bonds. Logical extensions of these studies include the comparison of $\Delta \chi(\mathrm{D})$ values among different $\mathrm{HO}$ complexes to assess differences in AFS, and the relative sensitivity of $\Delta \chi_{\mathrm{ax}}$ (D) on the same four substrates among complexes of a given HO. Such studies with $\mathrm{C} d \mathrm{HO}$ and $\mathrm{hHO}$ are in progress.

\section{Supplementary Material}

Refer to Web version on PubMed Central for supplementary material.

\section{Acknowledgements}

This work was supported, in part, by the National Institutes of Health, GM62830 (GNL) and EB002064 (KMS), and a Grant-in-Aid for Scientific Research (16570102) from the Ministry of Education and Sports, Science and Teaching, Japan (T.Y.)

\section{References}

1. Tenhunen R, Marver HS, Schmid R. J Biol Chem 1969;244:6388-6394. [PubMed: 4390967]

2. Yoshida T, Migita CT. J Inorg Biochem 2000;82:33-41. [PubMed: 11132636]

3. Wilks A. Antioxidants Redox Signal 2002;4:603-614.

4. Frankenberg-Dinkel N. Antoxidants Redox Signal 2004;6:825-834.

5. Ortiz de Montellano, PR.; Auclair, K. The Porphryin Handbook. Kadish, KM.; Smith, KM.; Guilard, R., editors. Elsevier Science; San Diego, CA: 2003. p. 175-202.

6. Rivera M, Zeng Y. J Inorg Biochem 2005;99:337-354. [PubMed: 15598511]

7. Maines MD. Annual Review of Pharmacological Toxicology 1997;37:517-554.

8. Beale SI. Ciba Foundation Symposium 1994;180:156-168. [PubMed: 7842851]

9. Ortiz de Montellano PR. Acct Chem Res 1998;31:543-549.

10. Davydov RM, Yoshida T, Ikeda-Saito M, Hoffman BM. J Am Chem Soc 1999;121:10656-10657.

11. Lad L, Schuller DJ, Shimizu H, Friedman J, Li H, Ortiz de Montellano PR, Poulos TL. J Biol Chem 2003;278:7834-7843. [PubMed: 12500973]

12. Sugishima M, Sakamoto H, Noguchi M, Fukuyama K. Biochemistry 2003;42:9898-9905. [PubMed: 12924938]

13. Sugishima M, Migita CT, Zhang X, Yoshida T, Fukuyama K. Eur J Biochem 2004;271:4517-4525. [PubMed: 15560792]

14. Schuller DJ, Zhu W, Stojiljkovic I, Wilks A, Poulos TL. Biochemistry 2001;40:11552-11558. [PubMed: 11560504]

15. Friedman JM, Lad L, Deshmukh R, Li HY, Wilks A, Poulos TL. J Biol Chem 2003;278:3465434659. [PubMed: 12819228]

16. Hirotsu S, Chu GC, Unno M, Lee D-S, Yoshida T, Park S-Y, Shiro Y, Ikeda-Saito M. J Biol Chem 2004;279:11937-11947. [PubMed: 14645223]

17. Friedman J, Lad L, Li H, Wilks A, Poulos TL. Biochemistry 2004;43:5239-5245. [PubMed: 15122889]

18. Unno M, Matsui T, Chu GC, Coutoure M, Yoshida T, Rousseau DL, Olson JS, Ikeda-Saito M. J Biol Chem 2004;279:21055-21061. [PubMed: 14966119]

19. Caignan GA, Deshmukh R, Wilks A, Zeng Y, Huang H-w, Moenne-Loccoz P, Bunce RA, Eastman MA, Rivera M. J Am Chem Soc 2002;124:14879-14892. [PubMed: 12475329]

20. La Mar GN, Asokan A, Espiritu B, Yeh DC, Auclair K, Ortiz de Montellano PR. J Biol Chem 2001;276:15676-15687. [PubMed: 11297521]

21. Li Y, Syvitski RT, Auclair K, Wilks A, Ortiz de Montellano PR, La Mar GN. J Biol Chem 2002;277:33018-33031. [PubMed: 12070167] 
22. Li Y, Syvitski RT, Auclair K, Ortiz de Montellano PR, La Mar GN. J Am Chem Soc 2003;125:1339213403. [PubMed: 14583035]

23. Syvitski RT, Li Y, Auclair K, Ortiz de Montellano PR, La Mar GN. J Am Chem Soc 2002;124:1429614297. [PubMed: 12452690]

24. Li Y, Syvitski RT, Chu GC, Ikeda-Saito M, La Mar GN. J Biol Chem 2003;279:6651-6663. [PubMed: 12480929]

25. Liu Y, Zhang X, Yoshida T, La Mar GN. Biochemistry 2004;43:10112-10126. [PubMed: 15287739]

26. Liu Y, Zhang X, Yoshida T, La Mar GN. J Am Chem Soc 2005;127:6409-6422. [PubMed: 15853349]

27. Wagner G, Pardi A, Wüthrich K. J Am Chem Soc 1983;105:5948-5949.

28. Harris TK, Mildvan AS. Prot Struct Funct Genet 1999;35:275-282.

29. Antonini, E.; Brunori, M. Hemoglobin and Myoglobin and Their Reactions with Ligands. Elsevier, North-Holland Publishing; Amsterdam: 1971. p. 40-54.

30. Sun J, Wilks A, Ortiz de Montellano PR, Loehr TM. Biochemistry 1993;32:14151-14157. [PubMed: 8260499]

31. Takahashi S, Wang JL, Rousseau DL, Ishikawa K, Yoshida T, Takeuchi N, Ikeda-Saito M. Biochemistry 1994;33:5531-5538. [PubMed: 8180175]

32. Chu GC, Tomita T, Sönnichsen FD, Yoshida T, Ikeda-Saito M. J Biol Chem 1999;274:24490-24496. [PubMed: 10455111]

33. Chu GC, Katakura K, Zhang X, Yoshida T, Ikeda-Saito M. J Biol Chem 1999;274:21319-21325. [PubMed: 10409691]

34. Ratliff M, Zhu M, Deshmukh R, Wilks A, Stojiljkovic I. J Bacteriol 2001;183:6394-6403. [PubMed: 11591684]

35. Caignan GA, Deshmukh R, Zeng Y, Wilks A, Bunce RA, Rivera M. J Am Chem Soc 2003;125:1184211852. [PubMed: 14505406]

36. Zeng Y, Deshmukh R, Caignan GA, Bunce RA, Rivera M, Wilks A. Biochemistry 2004;43:52225238. [PubMed: 15122888]

37. Caughey, WS. Hemes and Hemoproteins. Chance, B.; Estabrook, RW.; Yonetani, T., editors. Academic Press; New York: 1966. p. 276-277.

38. Cowgill RW, Clark WM. J Biol Chem 1952;198:33-61. [PubMed: 12999715]

39. Brunori M, Amiconi G, Antonini E, Wyman J, Zito R, Rossi-Fanolli A. Biochem Biophys Acta 1968;154:315-322. [PubMed: 5637052]

40. McGrath TM, La Mar GN. Biochim Biophys Acta 1978;534:99-111. [PubMed: 26418]

41. Brackett GC, Richards DL, Caughey WS. J Chem Phys 1971;54:4383-4401.

42. Kao Y-H, Lecomte JTJ. J Am Chem Soc 1993;115:9754-9762.

43. Clark K, Dugad LB, Bartsch RG, Cusanovich MA, La Mar GN. J Am Chem Soc 1996;118:46544664.

44. Déméné H, Tsan P, Gans P, Marion D. J Phys Chem B 2000;104:2559-2569.

45. Asokan A, de Ropp JS, Newmyer SL, Ortiz de Montellano PR. J Am Chem Soc 2001;123:42434254. [PubMed: 11457190]

46. Bertini I, Luchinat C. Coord Chem Rev 1996;150:1-296.

47. Kurland RJ, McGarvey BR. J Magn Reson 1970;2:286-301.

48. La Mar, GN.; Satterlee, JD.; de Ropp, JS. The Porphyrins Handbook. Kadish, KM.; Smith, KM.; Guilard, R., editors. 5. Academic Press; San Diego: 2000. p. 185-298.

49. Kolczak U, Hauksson JB, Davis NL, Pande U, de Ropp JS, Langry KC, Smith KM, La Mar GN. J Am Chem Soc 1999;121:835-843.

50. Johnston PD, Figueroa N, Redfield AG. Proc Natl Acad Sci USA 1979;76:3130-3134. [PubMed: 386331]

51. Piotto M, Sandek V, Sklenar V. J Biomol NMR 1992;2:661-666. [PubMed: 1490109]

52. Jeener J, Meier BH, Bachmann P, Ernst RR. J Chem Phys 1979;71:4546-4553.

53. Griesinger C, Otting G, Wüthrich K, Ernst RR. J Am Chem Soc 1988;110:7870-7872.

54. Bax A, Davis DG. J Magn Reson 1985;65:355-360. 
55. Williams G, Clayden NJ, Moore GR, Williams RJP. J Mol Biol 1985;183:447-460. [PubMed: 2991533]

56. Emerson SD, La Mar GN. Biochemistry 1990;29:1556-1566. [PubMed: 2334714]

57. Neal S, Nip AM, Zhang H, Wishart DS. J Biomol NMR 2003;26:215-240. [PubMed: 12766419]

58. Cross KJ, Wright PE. J Magn Reson 1985;64:220-231.

59. Walker, FA. The Porphyrin Handbook. Kadish, KM.; Smith, KM.; Guilard, R., editors. 5. Academic Press; Boston: 2000. p. 1-183.

60. Budd DL, La Mar GN, Langry KC, Smith KM, Nayyir-Mazhir R. J Am Chem Soc 1979;101:60916096.

61. Hansch C, Leo A, Taft RW. Chem Rev 1991;91:165-195.

62. Buchler JW, Kokisch W, Smith PD. Struct Bonding 1982;34:79-132.

63. Ma L-H, Liu Y, Zhang X, Yoshida T, La Mar GN. J Am Chem Soc 2006;128in press

64. Koenigs Lightning L, Huang H-W, Moënne-Loccoz P, Loehr TM, Schuller DJ, Poulos TL, Ortiz de Montellano PR. J Biol Chem 2001;276:10612-10619. [PubMed: 11121422]

65. Fujii H, Zhang X, Tomita T, Ikeda-Saito M, Yoshida T. J Am Chem Soc 2001;123:6475-6484. [PubMed: 11439033]

\section{ABBREVIATIONS}

AFS

axial field strength

HO

heme oxygenase

NmHO

Neisseria meningitidis heme oxygenase

NOESY

two-dimensional nuclear Overhauser spectroscopy

TOCSY

two-dimensional total correlation spectroscopy

DSS

2,2-dimethyl-2-silapentane-5-sulfonate

PH

protohemin

2M4VDH

2-methyl,4-vinyldeuterohemin

2F4VDH

2-formyl,4-vinyldeuterohemin

DMDH

2-,4-dimethyldeuterohemin 


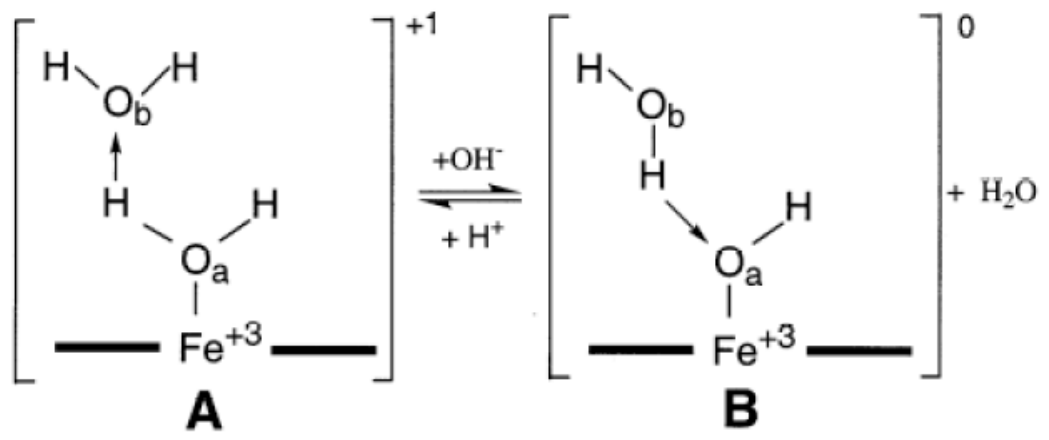

Figure 1.

Depiction of a ligated water $a(\mathbf{A})$ in equilibrium with an iron-ligated hydroxide $(\mathbf{B})$. In the absence of H-bond donation, ligated water $a$ is a weak-field ligand. Upon serving as an H-bond donor to a protein-based (or ordered water molecule $b$ ) acceptor, the axial field strength increases, until in the limit of complete transfer, as in $(\mathbf{B})$, results in the strong-field hydroxide ligand. 


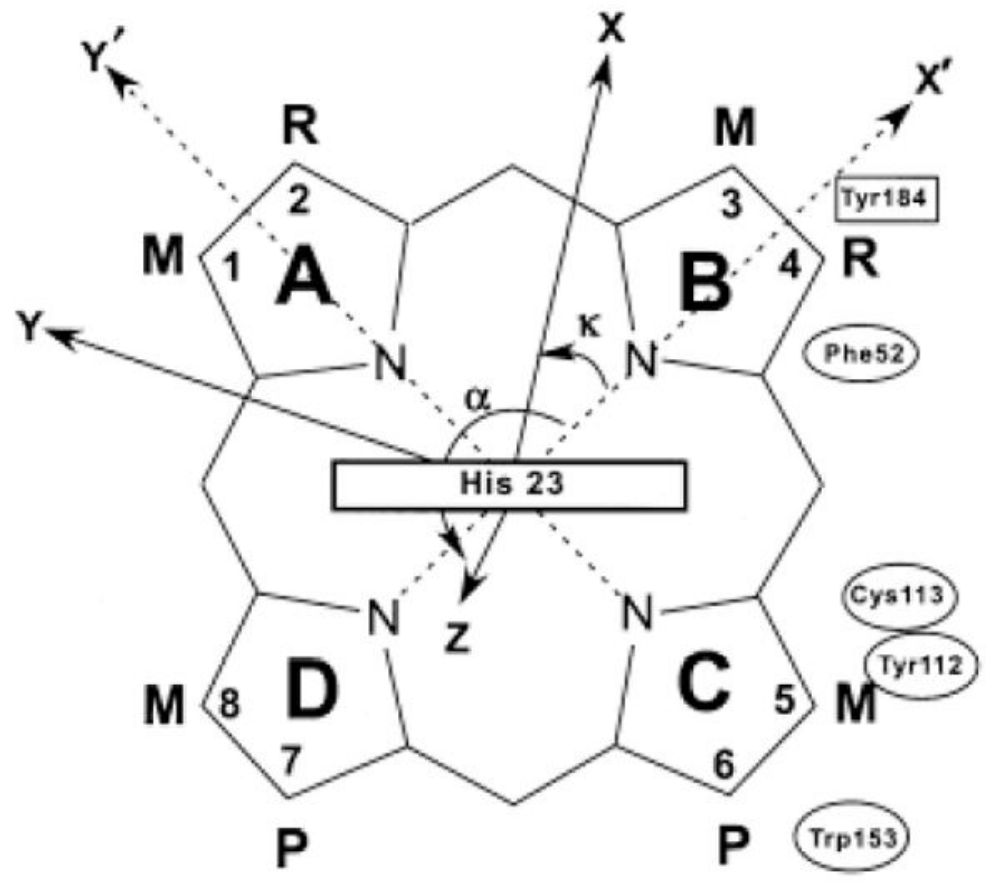

Figure 2.

Structure of the hemin substrates with $\mathrm{R}_{2}=\mathrm{R}_{4}=\mathrm{CH}_{3}$ (2,4-dimethyldeuterohemin, DMDH); $\mathrm{R}_{2}=\mathrm{CH}_{3}, \mathrm{R}_{4}=$ vinyl (2-methyl,4-vinyldeuterohemin, 2M4VDH); $\mathrm{R}_{2}=\mathrm{R}_{4}=$ vinyl (protohemin), and $\mathrm{R}_{2}=$ formyl, $\mathrm{R}_{4}$ = vinyl (2-formyl,4-vinyldeuterohemin; 2F4VDH) with labeling by the Fischer notation, as viewed from the proximal side of $N m \mathrm{HO}$. Also shown is the position of the axial His23 imdiazole plane. The reference coordinate system, $x^{\prime}, y^{\prime}, z^{\prime}$, has $x^{\prime}, y^{\prime}$ in the mean heme plane and passing through $\mathrm{N}_{\mathrm{B}}, \mathrm{N}_{\mathrm{A}}$, respectively, with $\mathrm{z}$ ' pointing to the proximal side. The magnetic axes, $\mathrm{x}, \mathrm{y}, \mathrm{z}$, where the axially symmetric $\chi$ is diagonal, are defined by the tilt of the major magnetic axis, $z$, from the heme normal, $z$ ', by the angle $\beta$ (not shown), and the direction of the tilt of the major magnetic axis $\mathrm{z}$, is defined by angle $\alpha$, between projection of $\mathrm{z}$ on the $\mathrm{x}^{\prime}, \mathrm{y}^{\prime}$ plane and the $\mathrm{x}^{\prime}$ axis. For the present complex, $\Delta \chi_{\mathrm{rh}}=0$ and $\kappa$ becomes irrelevant. 


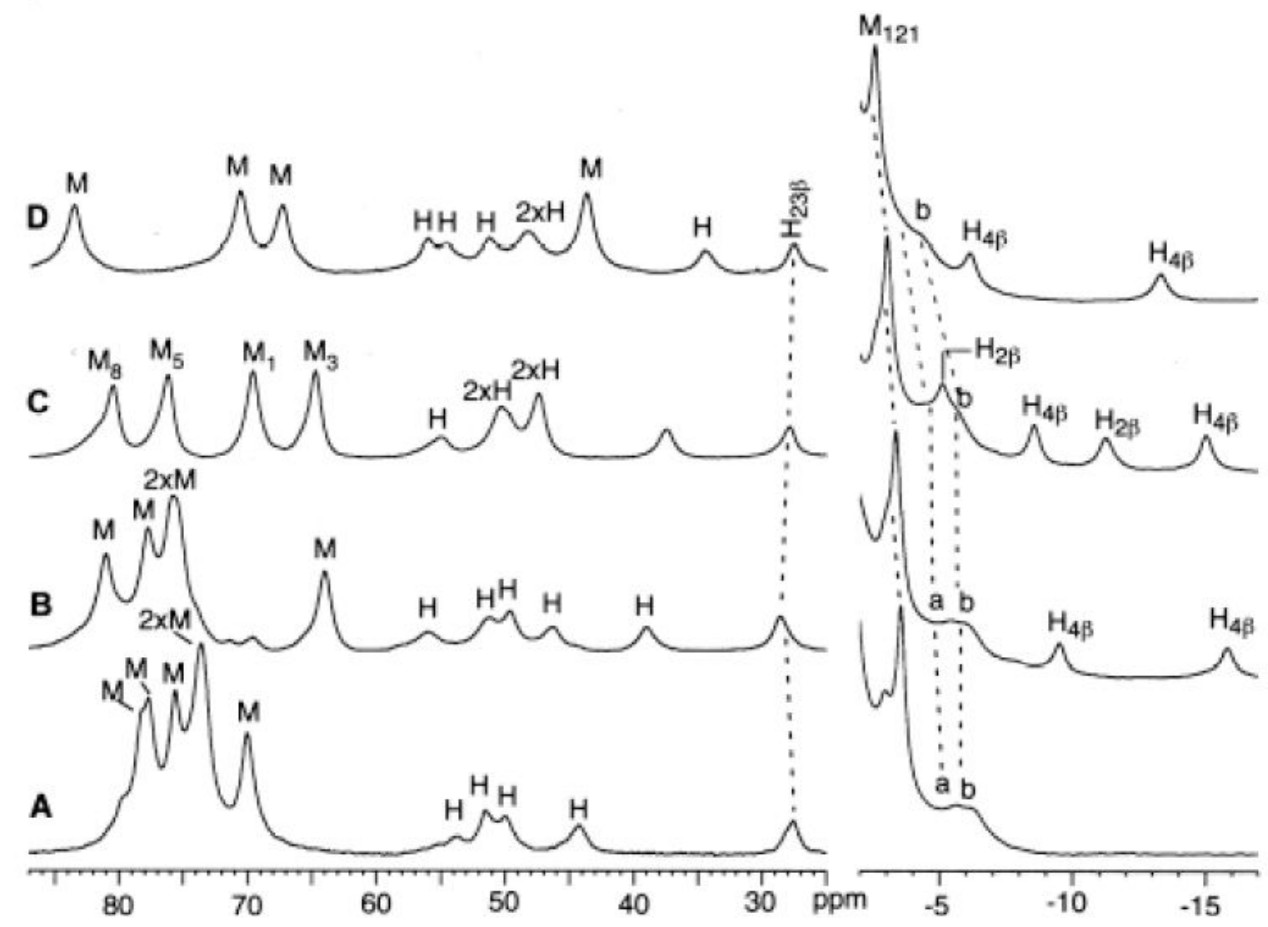

Figure 3.

Resolved portions of the $500 \mathrm{MHz}{ }^{1} \mathrm{H}$ NMR spectra of high-spin ferric resting state complexes in ${ }^{2} \mathrm{H}_{2} \mathrm{O}, 50 \mathrm{mM}$ in phosphate at $25^{\circ} \mathrm{C}$ : (A) $N m \mathrm{HO}-\mathrm{DMDH}-{ }^{2} \mathrm{H}_{2} \mathrm{O}$ at pH 7.2; (B)

$\mathrm{NmHO}-2 \mathrm{M} 4 \mathrm{VDH}-{ }^{2} \mathrm{H}_{2} \mathrm{O}$ at $\mathrm{pH} 7.0$; (C) $N m \mathrm{HO}-\mathrm{PH}_{-}{ }^{2} \mathrm{H}_{2} \mathrm{O}$ at $\mathrm{pH} 7.0$; and (D)

NmHO-2F4VDH- ${ }^{2} \mathrm{H}_{2} \mathrm{O}$ at $\mathrm{pH}$ 6.8. Heme methyl peaks are labeled $\mathrm{M}$ and single protons $\mathrm{H}$, with a subscript in the Fischer notation if the peak has been assigned. ${ }^{26}$ Amino acid residue signals are identified by the residue number and position. The peak $a$ was assigned to Ala121 $\mathrm{C}_{\alpha} \mathrm{H}$ on the basis of the NOE to Ala121 $\mathrm{C}_{\beta} \mathrm{Hs}$ in $N m \mathrm{HO}-\mathrm{PH}-\mathrm{H}_{2} \mathrm{O} .{ }^{26}$ Peak $b\left(\mathrm{~T}_{1} \sim 3 \mathrm{~ms}\right)$ in $\mathrm{Nm} \mathrm{HO}-\mathrm{PH}-\mathrm{H}_{2} \mathrm{O}$ was not detectable because it resonates under the more weakly relaxed vinyl $2 \mathrm{H}_{\beta}$ peak. The presence of peak $b$ is made obvious in the DMDH complex in $\mathbf{A}$; its $\mathrm{T}_{1} \sim 3 \mathrm{~ms}$ and shift are consistent with prediction ${ }^{26}$ for Ser $117 \mathrm{C}_{\alpha} \mathrm{H}$. Nevertheless, both peaks $a$ and $b$ move to lower field in the same order as the Leu142 $\mathrm{C}_{\delta} \mathrm{Hs}\left(\mathrm{M}_{142}\right)$. 


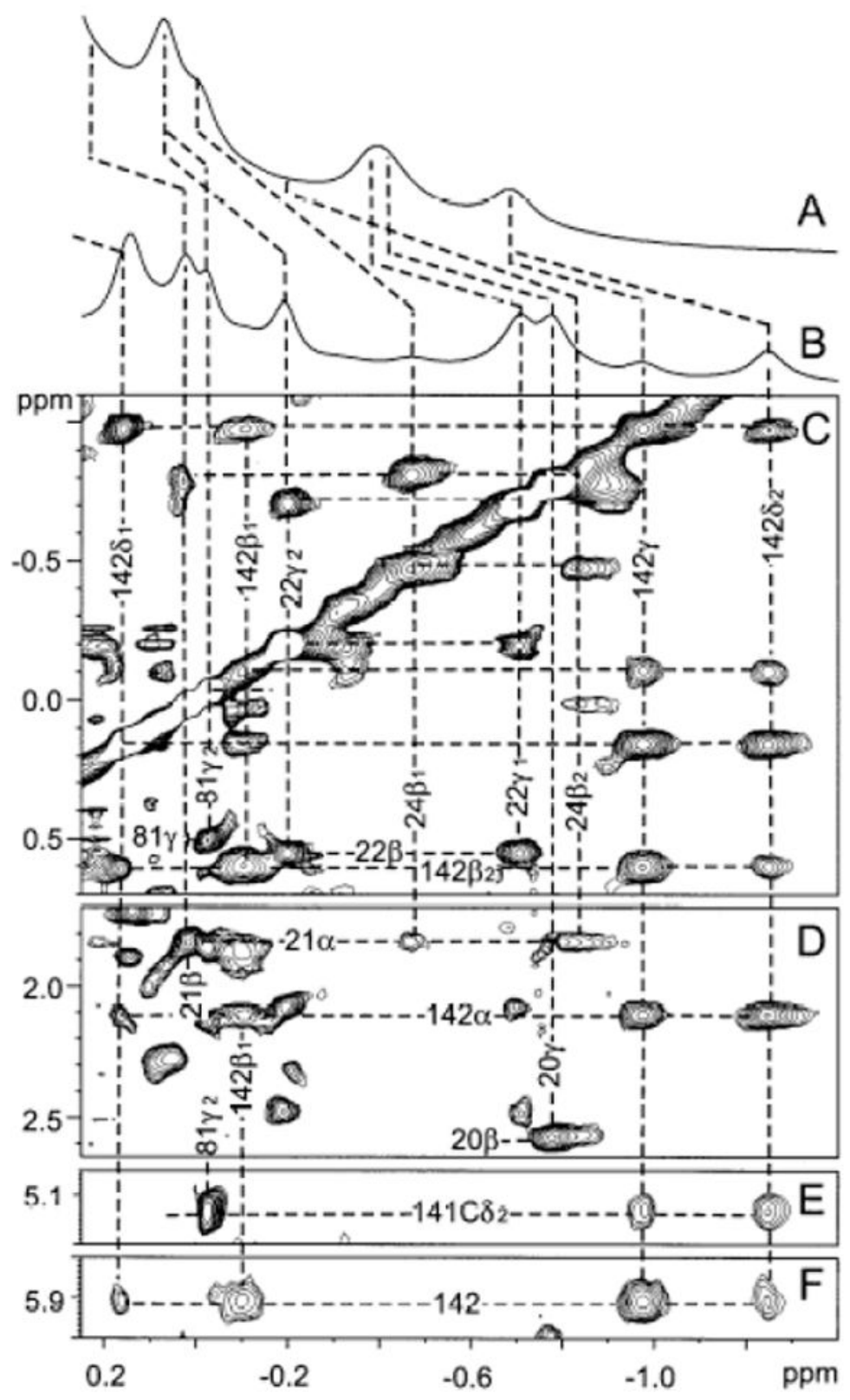

Figure 4.

Resolved upfield portions of the $600 \mathrm{MHz}{ }^{1} \mathrm{H}$ NMR spectrum, in ${ }^{2} \mathrm{H}_{2} \mathrm{O}, 100 \mathrm{mM}$ phosphate at $25^{\circ} \mathrm{C}$ of (A) $N m \mathrm{HO}-2 \mathrm{~F} 4 \mathrm{VDH}-{ }^{2} \mathrm{H}_{2} \mathrm{O}$ at $\mathrm{pH} 6.8$ and (B) $N m \mathrm{HO}-\mathrm{DMDH}-{ }^{2} \mathrm{H}_{2} \mathrm{O}$ at $\mathrm{pH} 7.0$ illustrating the strong bias to lower field (smaller upfield dipolar shift) as electron withdrawing substituents are introduced into the heme periphery. Portions of the $600 \mathrm{MHz}$ NOESY spectrum (mixing time $40 \mathrm{~ms}$, repetition rate $2 \mathrm{~s}^{-1}$ ) for $\mathrm{NmHO}-\mathrm{DMDH}-{ }^{2} \mathrm{H}_{2} \mathrm{O}$ illustrate (C) intra-residue contacts for Val22, Asp24 and Leu142; (D) intra-residue contacts for Thr20 and Ala21 and inter-residue contacts between Ala21 and Asp24, Thr20 and Ala21; (E) inter-residue contact between Leu142 and His141, and (F) inter-residue contacts for Leu142. 


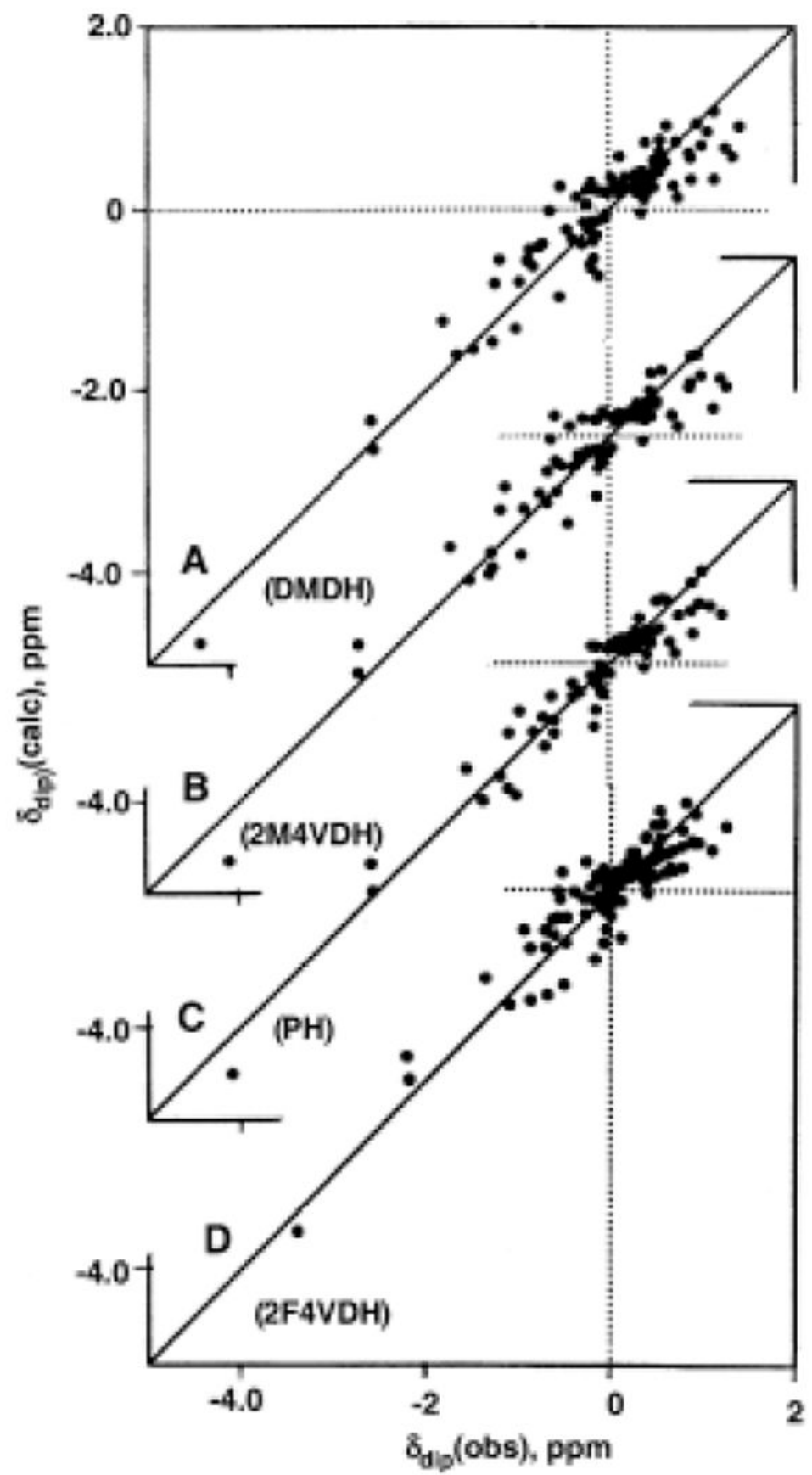

Figure 5.

Plot of $\delta_{\text {dip }}$ (obs) versus $\delta_{\text {dip }}$ (calc) for the optimized magnetic axes of: (A) NmHO-DMDH$\mathrm{H}_{2} \mathrm{O},\left(\Delta \chi_{\mathrm{ax}}=-2.72 \pm 0.08 \times 10^{-8} \mathrm{~m}^{3} / \mathrm{mol}\right),($ B $) N m \mathrm{HO}-2 \mathrm{M} 4 \mathrm{VDH}-\mathrm{H}_{2} \mathrm{O}$, with $\Delta \chi_{\mathrm{ax}}=-2.62 \pm$ $0.07 \times 10^{-8} \mathrm{~m}^{3} / \mathrm{mol},(\mathbf{C}) \mathrm{NmHO}-\mathrm{PH}-\mathrm{H}_{2} \mathrm{O}\left(\Delta \chi_{\mathrm{ax}}=-2.52 \pm 0.08 \times 10^{-8} \mathrm{~m}^{3} / \mathrm{mol}\right)$, and $(\mathbf{D})$ $N m \mathrm{HO}-2 \mathrm{~F} 4 \mathrm{VDH}-\mathrm{H}_{2} \mathrm{O}\left(\Delta \chi_{\mathrm{ax}}=-2.02 \pm 0.09 \times 10^{-8} \mathrm{~m}^{3} / \mathrm{mol}\right)$ resulting from a one parameter $\operatorname{search}\left(\Delta \chi_{\mathrm{ax}}\right)$ for the minimum in Eq. (3) with the $\chi$ oriented through the axial His $23 \mathrm{~N}_{\varepsilon}(\alpha=$ $210^{\circ}, \beta=7^{\circ}$ ) as found for $\mathrm{Nm} \mathrm{HO}-\mathrm{PH}-\mathrm{H}_{2} \mathrm{O} .^{26}$ 


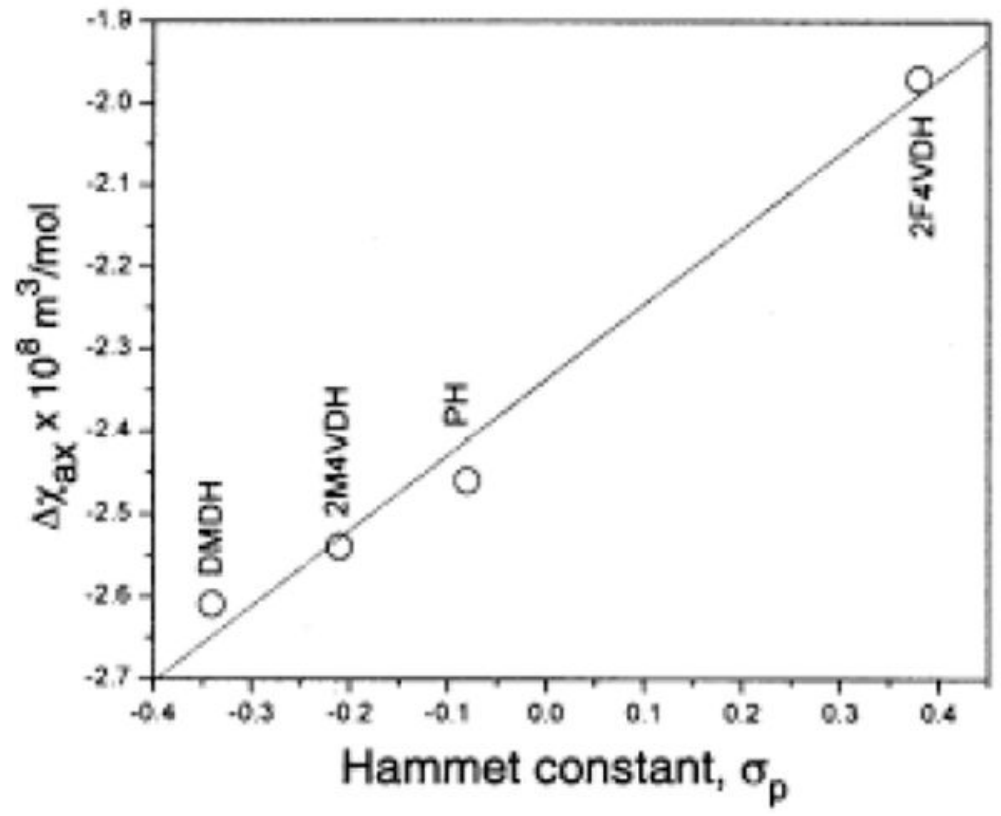

Figure 6.

Plot of the determined axial magnetic anisotropy, $\Delta \chi_{\mathrm{ax}}$, versus the sum of the Hammett $\sigma_{\mathrm{p}}$ constant $^{61}$ for substituents at positions 2 and 4 , that would be related to the basicity of the porphyrin for the four substrates in high-spin ferric, resting state $\mathrm{NmHO}$ complexes. 


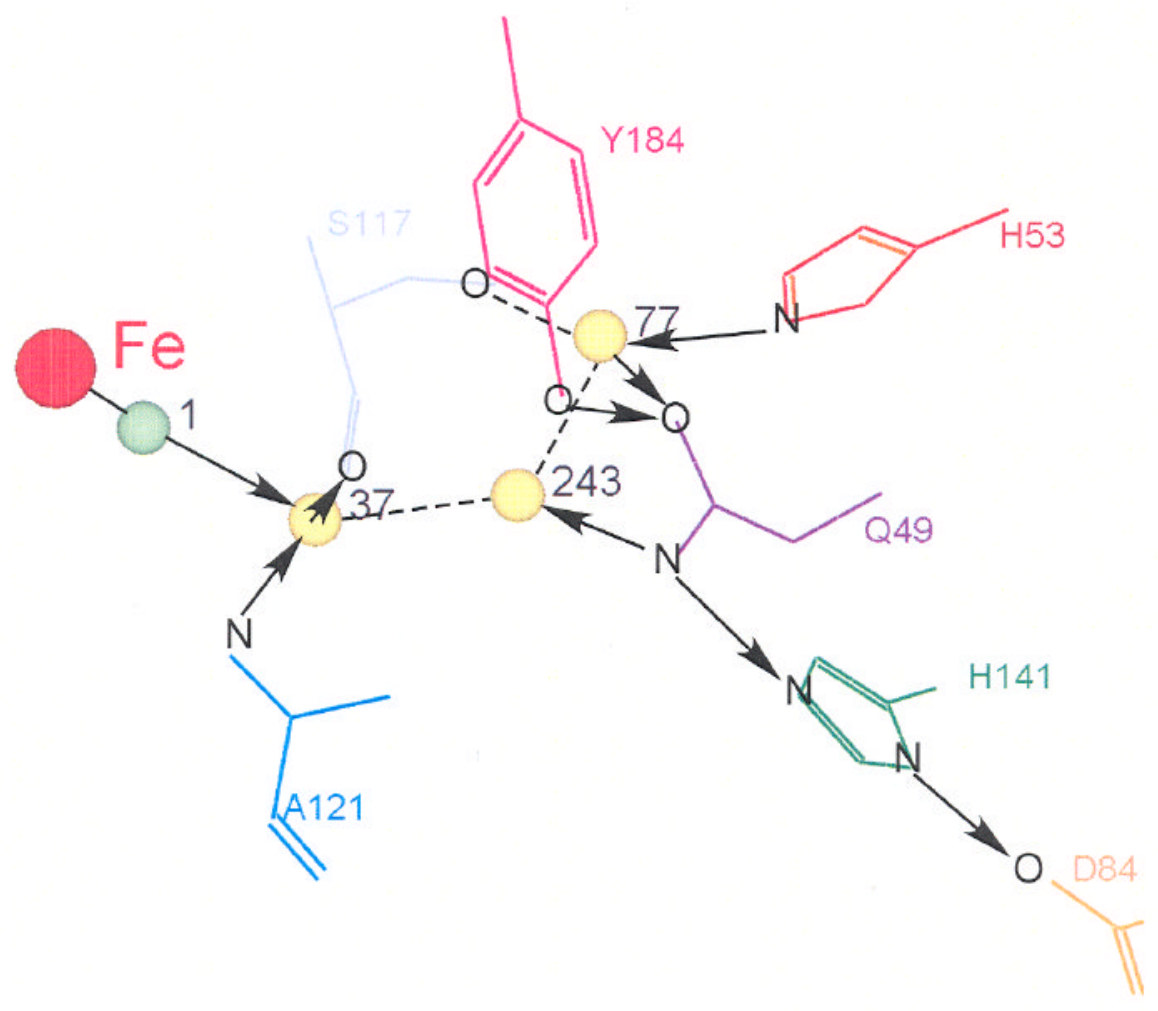

Figure 7.

Portion of the crystal structure ${ }^{14}$ active site of $\mathrm{NmHO}-\mathrm{PH}-\mathrm{H}_{2} \mathrm{O}$ that depicts the water molecule (\#1 in light green sphere) ligated to the heme iron (red sphere), as well as the three catalytically implicated non-ligated water molecules (\#37, \#77 and \#243) (yellow spheres), and residues which are directly (Gln49 (dark blue), His53 (brown), Ser117 (light blue), Ala121 (aqua), Tyr184 (magenta)) or indirectly (His141 (green), Asp84 (beige)) interact with one or more of these water molecules. Solid arrows indicate the known direction of the donor $\rightarrow$ acceptor in the implied H-bonds. The other H-bond interactions where the identities of acceptor/donor cannot be uniquely determined from crystallographic ${ }^{14}$ or $\mathrm{NMR}^{26}$ data, are shown in dashed lines. It is noteworthy that the ligated water \#1, and the two key distal H-bond network members Gln49 and His53 side chains, all necessarily serve as donors to one or another of the three catalytically implicated water molecules. 


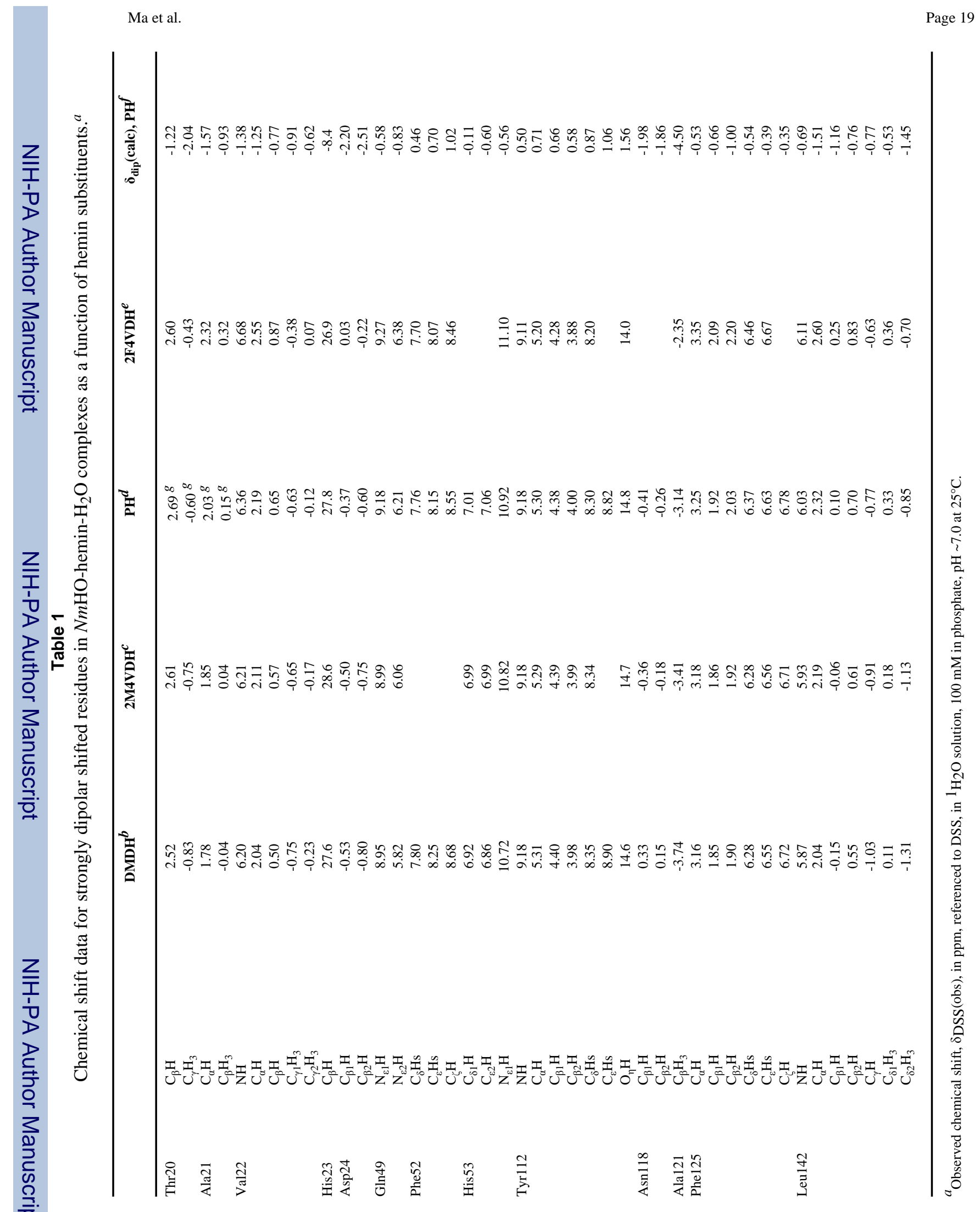




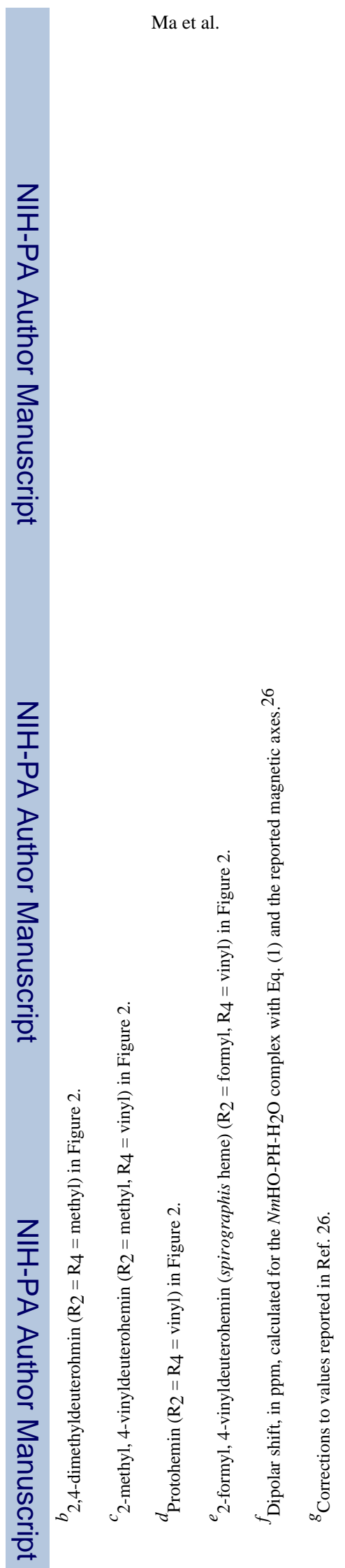

J Am Chem Soc. Author manuscript; available in PMC 2008 October 13. 


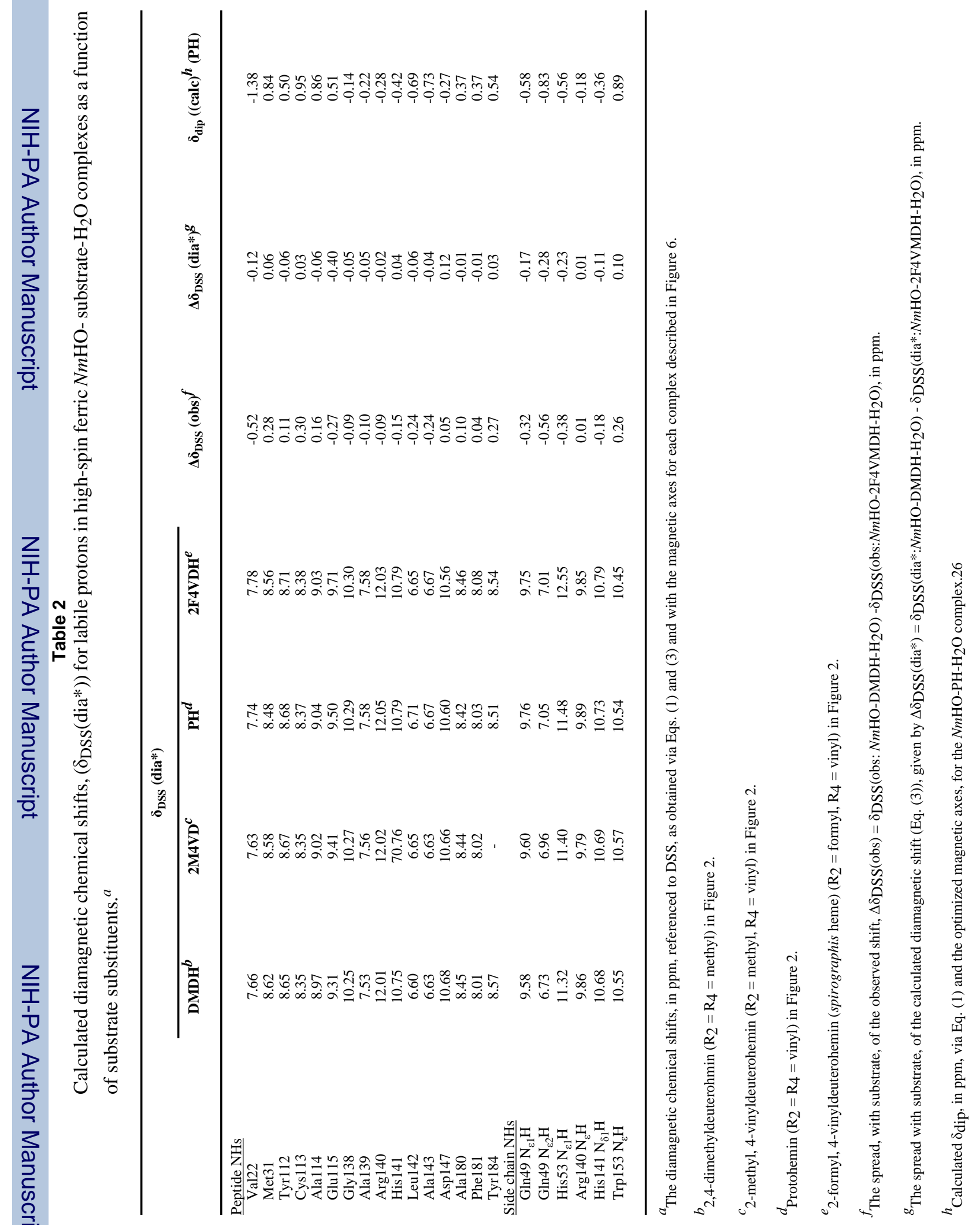

